\title{
The Breastfeeding in Adolescent Mothers
}

\author{
Adölesan Annelerde Emzirme
}

\author{
Gülşen Işsı $*^{*^{l}}$, Nuray Egelioğlu Cetişli ${ }^{l}$
}

\section{ÖZET}

Dünya Sağlık Örgütü, adölesan dönemini 10-19 yaşları arasındaki dönem olarak tanımlamakta ve dünyada her altı kişiden birinin adölesan olduğunu bildirmektedir. Bu dönemde gerçekleşen fiziksel ve psikolojik değişiklikler, madde bağımlılığı, korunmasız cinsel ilişki ve istenmeyen gebelikler gibi bazı riskli davranışlara neden olabilmektedir. Hem gelişmiş, hem de gelişmekte olan ülkelerde adölesan gebelikler önemli bir sağlık sorunudur. Adölesan gebeliğin risk faktörleri, çok yönlü ve karmaşıktır. Abortus, erken doğum tehditi, gebelikte hipertansiyon, anemi, düşük doğum ağırlığı, konjenital anomali riski, artmış neonatal mortalite ve emzirme problemleri bunlar arasında sayılabilir. Birçok açıdan riskli bir dönemde olan adölesan anneler arasında emzirmeye başlama, emzirmeye devam etme oranlarının az olması da, anne ve bebeğin sağlığını olumsuz etkileyen ve göz ardı edilen önemli sorunlardandır. Düşük sosyoekonomik durum, partner yokluğu, sosyal destek yetersizliği, olumsuz anne ve eş desteği, ağrı, kültürel etkiler, bilgi eksikliği, olumsuz deneyimler, emzirme niyeti, emzirmeye ilişkin tutum ve öz-yeterlilik emzirmeyi etkileyen faktörler olarak belirtilmektedir.

Anahtar kelimeler: Adölesan, annelik, emzirme

\begin{abstract}
World Health Organization defined the adolescent period between the ages of 10-19 and declared that one out of every six people are adolescent. Physical and psychological changes in this period might cause risky behaviors such as drug abuse, sexual intercourse with no protection and unwanted pregnancy. Adolescent pregnancies are an important health problem in both developed and developing countries. Risk factors of adolescent pregnancy are complicated and miscellaneous. Abortus, threat of premature birth, hypertension in pregnancy, anemia, low weight of the newborn, congenital anomaly risk, increased neonatal mortality and breast feeding problems are some of them. For adolescent mothers, who are in a risky period for many aspects, low rates of starting and continuing breast feeding is another important and neglected problem affecting mother's and newborn's health negatively. Low socio-economic condition, absence of partner, inadequate social support, negative support of parents and couple, pain, cultural factors, lack of knowledge, negative experiences, breast feeding intention, manner regarding breast feeding and self-sufficiency were reported as factors affecting the breast feeding.
\end{abstract}

Key words: Adolescent, motherhood, breastfeeding

Received / Geliş tarihi: 05.12.2016, Accepted / Kabul tarihi: 26.01.2017

${ }^{1}$ İzmir Kâtip Çelebi Üniversitesi Sağlık Bilimleri Fakültesi Hemşirelik Bölümü Kadın Sağlığı ve Hastalıkları Hemşireliği Anabilim Dalı

*Address for Correspondence / Yazışma Adresi: Gülşen Işsk. İzmir Kâtip Çelebi Üniversitesi Sağlık Bilimleri Fakültesi Hemşirelik Bölümü Kadın Sağlığı ve Hastalıkları Hemşireliği Anabilim Dalı Balatçık Kampüsü Çiğli Ana Yerleşkesi, Merkezi Ofisler 1, Çiğli, İzmir, E-mail: glsen20@ gmail.com Işık G, Cetişli NE. Adölesan Annelerde Emzirme, TJFMPC, 2017;11(1): 50-58.

DOI: $10.21763 /$ tjfmpc.296329 


\section{GíRIŞ}

Dünya Sağlık Örgütü (DSÖ) ve Birleşmiş Milletler Nüfus Fonu (UNFPA), adölesan dönemini 10-19 yaşları arasındaki dönem olarak tanımlamakta ve dünyada her altı kişiden birinin adölesan olduğunu bildirmektedir. ${ }^{1,2,3}$ Amerikan Psikiyatri Birliği (APA, 2002) ise; adölesan dönemini fiziksel, bilişsel, davranışsal ve bireysel otonomi düzeyinin arttığı çocukluktan yetişkinliğe geçilen bir dönem olarak belirtmektedir. ${ }^{1,4,5} \mathrm{Bu}$ dönemdeki fiziksel ve psikolojik değişiklikler, madde bağımlılığı, korunmasız cinsel ilişki ve istenmeyen gebelikler gibi bazı riskli davranışlara neden olabilmektedir. ${ }^{6}$

Hem sağlık nedenleri, hem de sosyal nedenlerden dolayı adölesan doğurganlık konusu önem taşımaktadır. Dünya Sağlık Örgütü, 15-19 yaşları arasında yaklaşık 16 milyon kız olduğunu, her y1l 15 yaşın altındaki bir milyon kızın doğum yaptığını bildirmiştir. Dünya çapındaki tüm doğumların, \%11'i, 15-19 yaşları arasındaki adölesanlar tarafindan yapılmaktadır. $\mathrm{Bu}$ doğumların \%95'i, düşük ve orta gelirli ülkelerde meydana gelmektedir. ${ }^{7}$ Türkiye Nüfus ve Sağlık Araştırması (TNSA) 2013 verilerine göre, Türkiye'de adölesanlar genel popülasyonun $\% 26$ 'sını oluşturmakta, bunların \%16,2' si evli, \%5'i ise çocuk sahibi olmaya başlamıştır. ${ }^{8}$ Türkiye İstatistik Kurumu (TÜİK) 2015 verilerine göre ise, 15-19 yaş grubundaki her bin kadın başına 25 doğum düşmektedir. ${ }^{9}$

Erken doğum, abortus, düşük doğum ağırlığı, konjenital anomali, eklampsi gibi gebelik ve doğum sirasinda meydana gelen komplikasyonlar, adölesan gebeliklerin riskli gebelikler olarak kabul edilmesine neden olmaktadır. Maternal ölümlerin \%13'ünü adölesanlar oluşturmakta ve adölesan gebeliklerde neonatal mortalite oranı artmaktadır. ${ }^{10,11,12}$ Adölesan annelerden doğan bebeklerin, 20-24 yaşlarındaki kadınlardan doğan bebeklere göre hastalık ve ölüm riskleri daha fazladır. ${ }^{7}$ Adölesan annelerin bebeklerinde düşük doğum ağırlıklı olma, prematürite, gelişimsel ve öğrenme zorlukları ve beslenme problemleri daha fazla görülmektedir. ${ }^{13,14}$ Adölesan annelerden doğan bebeklerin beslenme ihtiyaçları son derece önemlidir. ${ }^{15}$ Anne sütünün, yenidoğan için kişiselleştirilmiş ilaç olduğu ve adölesan annelerin prematüre ve düşük doğum ağırlıklı doğma riski olan bebekleri için ayrıca önemli olduğu bildirilmektedir. ${ }^{16}$ Bir çok açıdan riskli bir dönemde olan adölesanlar arasında, yenidoğanı emzirme uygulamasının eksikliği ve emzirme oranının az olması da bilinen küresel halk sağlığı sorunlarındandır. Adölesan annelerin bebekleri için emzirme çok önemli olmasına rağmen, yenidoğan beslenmesi adölesanlar için kompleks bir olay olabilmektedir. ${ }^{17} \mathrm{Bu}$ derlemenin amacı, adölesan annelerdeki emzirme durumunu ve emzirmeyi etkileyen faktörleri incelemektir.

\section{Adölesan Annelerde Emzirmenin Yararları}

Emzirme; anne, bebek ve çocuk ölüm oranlarını azaltmada en önemli faktörlerden biridir ve hem anne, hem de yenidoğan için birçok faydası bulunmaktadır. ${ }^{16}$ Çeşitli rahatsızlıklara karşı, anne sütü benzersiz bir koruma sağlar. Bağışıklık sistemi, sindirim sistemi ve beyin gelişiminin yanı sıra, solunum yolları ve gastrointestinal sistem enfeksiyonlarının görülmesini azaltır ve genel büyümeyi içeren yenidoğan sağlığına ilişkin birçok yarar sağlar. ${ }^{18,19,20,21,22}$ Tartışmasız adölesan kadınlar da, emzirmeden büyük fayda sağlamaktadırlar. Örneğin, düşük gelirli olmaya eğilimli adölesan anneler için ekonomiktir ve sağlık giderlerini azaltmada katkısı vardır. Ayrıca tekrarlayan gebeliklerin yüksek olduğu bu grupta, emzirmeyle birlikte olan laktasyonel amenore doğum aralıklarının artmasına yardımcı olarak fayda sağlayabilmektedir. Annelerin, gebelik öncesi kilolarına hızla dönmelerini sağlar ve obez ya da çok kilolu olmalarını önler. Annelerin, annelik öz güvenini ve anne-bebek bağlanmasını artırıp, depresyon riskini azaltır ve emzirme süresinin uzamasındaki kararlarını da olumlu olarak etkilemektedir. ${ }^{17,20,21,22,23,24}$

\section{Adölesan Annelerde Emzirme Oranları}

Tüm ülkelerde, adölesan annelerin emzirmeye başlama ve emzirmeyi devam ettirme oranı, yetişkin annelere göre daha düşüktür ve birçok adölesan 6 haftadan daha az süre emzirmeyi devam ettirmektedir. ${ }^{17,25,26,27} \quad$ Amerika'da (2014) yayınlanan emzirme raporunda, genel emzirme oranı \%79,2, ilk 6 ayda sadece anne sütü verme oranı ise $\% 18,8$ olarak belirtilmiştir. ${ }^{28}$ Center for Disease Control (CDC) 2011 raporuna göre ise, 20 yaş ve altındaki annelerin yalnızca \%19,3'ü, 20-29 yaş arasındaki kadınların \%36,4'ü, 30 yaş ve üzeri kadınların ise \%45'i 3 ay boyunca sadece anne sütü vermektedir. $^{29}$ Yetişkinlerle kıyaslandığında, Ontorio'daki adölesanlarda taburcu olduğunda sadece anne sütü ile emzirme oranı \%27'dir. ${ }^{30,31}$ İngiltere'de yapılan postpartum, ilk altı haftada annelerin emzirme oranlarının karşılaştırıldığ çalışmada, yetişkin annelerin 20 yaş altındaki annelere göre 5 kat daha fazla emzirdiği belirlenmiştir. ${ }^{32}$ Santo ve ark. (2007)'nın ${ }^{33}$ yaptığ 1 çalışmada, Brezilya'da adölesan annelerin yetişkin annelere göre, 6 aydan önce bebeklerine sadece anne sütü vermeyi terk etmelerinin 1.5 kat daha fazla olduğu bulunmuştur. ${ }^{33}$ Literatürde, adölesan gebelerin \%81-84'ünün, gebelikleri boyunca emzirmeye niyetinin olduğu belirtilmiş ${ }^{34,35,36}$ olmasına rağmen, gerçek emzirmeye bașlama oranı $\% 39$ ile \%69 arasında değişmektedir. ${ }^{34,36,37,38,39,40}$ 
Ayrıca yapılan çalışmalara göre, emzirmeye başlayan adölesanların yarısından fazlası, ilk ay içinde emzirmeyi bırakırken ${ }^{34,37,39}$, sadece \%18,722,6's1 6 ay emzirmeye devam etmektedir. ${ }^{41,42}$

\section{Adölesan Annelerde Emzirmeyi Etkileyen Faktörler}

Bebeklerini emzirme olasılığı az ve özel bir grup olan adölesan annelere ilişskin bilgi azdır. Adölesan annelerdeki emzirmemenin nedenlerinin, yetişkin anneler ile aynı olup olmadığı belirsizdir. ${ }^{43,44,45}$ Literatürde adölesan annelerde ekonomik durum, evlilik durumu, sosyal destek, anne ve eş desteği, ağr1, kültürel etkiler, bilgi eksikliği, olumsuz deneyimler, emzirme niyeti, emzirmeye ilişkin tutum ve öz-yeterlilik emzirmeyi etkileyen faktörler olarak belirtilmektedir. ${ }^{17,46}$

Amerika'da, düşük gelirli adölesan anneler arasında yapılan çalışmada, annelerin \%75'i hiç emzirmemiş ya da sadece bir hafta emzirmişlerdir. ${ }^{17}$ Adölesan annelerin, emzirmeye başlamalarıyla ilişskili faktörleri tespit etmek amacıyla Ohio'da yapılan retrospektif kohort çalışmada, 19 yaş ve altı 30.402 adölesan ile 19 yaş üzeri 257.840 yetişkinin emzirmeye başlama oranı karşılaştırılmıştır. Adölesan annelerin \%44'ü, yetişkin annelerin ise \%65'i emzirmeye başlamıştır. Çalışmada, emzirmeye başlamamaya neden olan en önemli faktörler; partner yokluğu, sağlık sigortasının ve sosyal desteğin olmaması olarak belirtilmiştir. ${ }^{47}$ Santo ve ark (2007)'nın ${ }^{33}$ çalışmasında da, düşük sosyoekonomik durum, emzirmeyle ilgili ağrı sorunlar1, meme ucu hasar1 ve mastit, partner yokluğu, negatif ailesel etki gibi faktörlerin adölesan annelerde emzirmenin erken bırakılmasıyla ilişki olduğu bildirilmiştir. ${ }^{33}$ Anne sütünün yetersiz olduğuna ilişkin alg1, sağma problemleri, emzirme tekniklerinde sorun yaşama, meme ve meme ucu ağrısı, okul ya da işe ayrılması gereken zaman, bunalmış ve hayal kırıklığına uğramış hissetmek adölesanlarda emzirmeyi birakma nedenleri olarak ifade edilmiştir. ${ }^{17,46,48,49,50,51}$ Ülkemizde yapılan, uluslararası literatürden faklı sonuçların elde edildiği Yılmaz ve ark. (2016)'nın ${ }^{52}$ çalışmasında, 15-19 yaş grubu 200 adölesan annenin emzirmeye başlama zamanı, ilk 6 ay boyunca sadece anne sütü verme oranı ve anne sütü vermeyi etkileyen faktörler incelenmiştir. Doğum sonrası, ilk bir saat içerisinde emzirmeye başlayanların oranı \%45,5 olarak bulunmuştur. Anne yaşı, annenin eğitim düzeyi, annenin çalışma durumu, aylık geliri, aile yapısı, sigara içme, düzenli antenatal bakım alma, yenidoğanın ağırlığı ve meme ucu problemleri ile emzirmeye erken ya da geç başlama zamanı arasında fark bulunmamıştır. Ancak emzirme eğitimi alan, planlı bir gebeliği olan, vajinal doğum yapan ve erkek bebeği olan anneler emzirmeye anlamlı olarak daha erken başlamışlardır. Emzirmeye erken başlayan kadınlar, iki saat içerisinde emzirmeye başlayan kadınlara göre daha uzun süre sadece anne sütü vermişler ve daha uzun süre bebeklerini emzirmişlerdir. ${ }^{52}$

Annenin, emzirme niyetinin olması emzirme için çok önemli bir itici güçtür. Leclair ve ark. $(2015)^{15}$ tarafından Ontorio'da yapılan retrospektif kohort çalışmada $(n=22.023)$ adölesanların emzirmeye başlama oranları ve emzirme niyetlerini etkileyen faktörler incelenmiştir. Annelerin, \%48,8'inin taburcu olurken bebeklerini sadece anne sütü ile besledikleri, ileri yaştaki adölesanların emzirme oranlarının daha yüksek olduğu, prenatal sınıfa katılma, yüksek gelirli çevrede yaşama, spontan vajinal doğum yapma, sigara içmeme, gebeliğinde madde kullanmama, gebeliğe ilişkin komplikasyon olmamasının emzirme niyetini olumlu etkilediği bildirilmiştir. Çalışma sonuçlarına göre, riskli gruplarda olan adölesan annelerin emzirme oranını artırmak için multidisipliner bakımın önemli olduğu vurgulanmaktadır. ${ }^{15}$

Hall-Smith ve ark. (2012) $)^{53}$ tarafindan yapılan çalışmada ise, adölesan annelerin emzirmeye ilişkin negatif düşüncelerinin, pozitif düşüncelere ağır bastığı ve emzirmeye ilişkin bilgi eksikliğinin bu olumsuz düşünce ve davranışların oluşmasına neden olduğu bildirilmiştir. ${ }^{53}$ Adölesan annelerin emzirmeyle ilgili pozitif deneyimlerinin, hastanede ve erken postpartum dönemde emzirmeye başlamalarında önemli bir faktör olduğu bulunmuş, hastaneden çıtıktan sonraki deneyimlerinin ise emzirmeye devam etme konusunda önemli olduğu belirtilmiştir. Emzirmeye ilişkin kültürel etkiler, toplum içerisinde emzirmekten utanma duygusu adölesan annelerin emzirmelerini olumsuz etkileyen faktörler olarak belirtilmiştir. ${ }^{17}$ Diğer çalışmalarda da, adölesanlar emzirmenin kişisel özgürlüklerinin kaybı olduğunu, annelik ve emzirmenin yaşamlarını bozduğunu belirtmişlerdir. ${ }^{46,50,54}$

Emzirmeyle ilișkili olan faktörlerden bir diğeri de, emzirme öz-yeterliliğidir. Düşük emzirme güveni ve öz yeterlilik, emzirmeye hazır hissetmeme adölesan anneler arasinda yaygındır. ${ }^{55,56,57}$ Öz-yeterlilik algıs1, bireyin istenilen davranışları başarıyla yerine getirebilme konusunda kendisine olan inancıdır. $\mathrm{Bu}$ algı ne kadar güçlü olursa, birey amaca ulaşmak için o kadar çok çaba sarf edecektir. ${ }^{58,59}$ Emzirme öz yeterliliği, emzirme süresini ve sadece anne sütü vermeyi tahmin etmektedir. Mossman ve arkadaşları $(2008)^{60}$ adölesan annelerin emzirme güven ve tutumlarının emzirmeyi başlatma ve süresi üzerine etkisini değerlendirmek amaciyla yaptıkları çalışmada $(\mathrm{n}=100)$, prenatal dönemdeki 
emzirme tutum puanı yüksek olan annelerin emzirme oranlarının daha yüksek ve emzirmeye devam etme sürelerinin daha uzun olduğu belirlenmiştir. $^{60}$

Adölesan annelerin, kendi anneleriyle birlikte yaşaması emzirme açısından önemlidir. Kendi anneleriyle birlikte yaşayan adölesan anneler, emzirmeyi erken birakma konusunda risk altındadırlar. Adölesan annelerin, kendi anneleri çoğunlukla torunlarının beslenmesiyle ilişkili kararlara katılmaktadır. Anneannelerin emzirme hakkında deneyimleri ve kişisel düşünceleri emzirme uygulamalarını zorlaştırabilir, ya da kolaylaştırabilir. Brezilya'da yapılan çalışmalarda, kendi anneleriyle birlikte yaşayan adölesanlarda, sadece anne sütü verme süresinin azaldığ 1 gösterilmiştir. ${ }^{61,62}$ de Oliveira ve ark., $(2014)^{41}$ tarafindan yapılan adölesan anneler ve onların annelerine sağlanan emzirme danışmanlık oturumlarının, sadece anne sütü verme süresi üzerine etkisinin incelendiği çalışmada $(n=323)$; emzirme danışmanlık oturumlarının, anneleriyle birlikte yaşayan adölesan annelerde 67 gün, anneleriyle birlikte yaşamayan adölesan annelerde ise 46 gün sadece anne sütü verme süresini arttırdığ $_{1}$ bulunmuştur. ${ }^{41}$

Adölesan babaların, emzirme konusundaki bilgi ve düşünceleri de önemlidir. Literatüre göre, babaların bilgi sahibi olmaları, annelerin emzirmeye devam etme potansiyelini artırmak için gereklidir. Chang ve arkadaşları (2012) ${ }^{63}$ erkeklerin emzirme hakkında bilgilerinin az olduğunu, kadınlara göre yapay beslenme konusunda daha pozitif olduğunu bildirmiştir. ${ }^{63}$ Sheriff ve arkadaşları (2009), ${ }^{64}$ Susin ve Giugliani (2008)' nn $^{65}$ çalışmalarında anne ve babalar emzirmenin doğal olarak gerçekleşeceğini beklediklerini ve genellikle bir zorlukla karşılaştıklarında da şaşırdıklarını ifade etmişlerdir. $\mathrm{Bu}$ çalışmalardan elde edilen sonuçlara göre, emzirmenin başlaması ve devam etmesine yardımcı olan baba desteği olumlu bir emzirme tutumudur ve babalar için yapılacak planlı eğitimler, emzirme oranını artırmaya katkı sağlamaktadır. ${ }^{64,65}$ Sipsma ve ark., $(2013)^{26}$ tarafindan yapılan çalışmada, eşinden şiddet gören adölesan annelerin daha kısa süre emzirdiği belirtilmiştir. ${ }^{26}$ Üniversite öğrencileri ile yapılan başka bir çalışmada da, erkeklerin kız öğrencilere göre emzirme konusunda daha az bilgili olduğu ve emzirme konusunda negatif bir tutuma sahip olduğu bulunmuştur. Öğrenciler branşlarına göre incelendiğinde ise, sağlıkla ilgili branşlarda olan öğrencilerin bilgi düzeyinin yüksek olduğu ancak emzirme tutumlarının farklılık göstermediği bildirilmiştir. ${ }^{66}$

\section{Adölesan Annelerde Emzirmeyi Arttıran Uygulamalar}

Adölesan anne popülasyonunda, emzirmeyi başlatmak ve devamlılığını sağlamak için anneyi desteklemede çeşitli müdahaleler bulunmaktadır. Bunlar, medya kampanyaları, danışmanlık, akran rol modelliği, grup oturumları ve eğitim aktivitelerini içeren antenatal programlar, hemşire ve ebelerin yaptığ1 postpartum ev ziyaretleridir. ${ }^{67,68,69,70}$ Brown ve arkadaşları $(2011)^{25}$ tarafından 17-24 yaş arasındaki 138 adölesan anne ile emzirmeye başlama ve süresi ile ilişkili faktörleri incelemek amacıyla yapılan retrospektif çalışmada, en az 6 ay boyunca emzirmenin; emzirme destek gruplarına katılma, emzirmenin kolay olacağına inanma, emzirmenin normal olduğu bir çevrenin parçası olma ve diğerleri tarafından emzirme konusunda teşvik edilme ile pozitif olarak ilişki olduğu bildirilmiştir. Adölesan annenin emzirme hakkında ne düşündüğünü bilmek de uzun süre emzirmeyi teşvik edebilmede önemlidir. ${ }^{25}$ Monterio ve ark. $(2014)^{71}$ tarafindan yapilan çalışmada adölesan annelerin çoğu; çalışmama, tek çocuğunun olması, doğum sonu ilk saatte emzirme gibi faktörlerin emzirme için uygun koşullar oluşturduğunu belirtmiştir.

Grassley'in $(2010)^{72}$, adölesan annelerin erken postpartum dönemde emzirmeyi başlatmada, hemşirelerden ihtiyaç duydukları sosyal destekleri belirlemek amacıyla yaptığı çalışmada, iletişim desteğinin emziren anneler için gerekli olduğu bildirilmiştir. Hemşirelerin, adölesanlara erken postpartum dönemde emzirmeye başlamaları konusunda sosyal destek vermesi, adölesanların uzun dönem sağlığını desteklemesi açısından önemlidir. $\mathrm{Bu}$ nedenle, hemşireler adölesan annelerin emzirmeye ilişkin pozitif deneyimlerini desteklemelidirler. $^{72}$ Yapılan bir sistematik derlemede, incelenen araştırmalarda katılımcılar; duygusal destek, takdir etme ve iletişim desteklerinin emzirme için daha fazla yardımcı olduğunu belirtmişlerdir. Katılımcılar, annelerinden aldığı desteğin kısmen daha güçlü olduğunu belirtmiştir. Adölesanlarla birlikte çalışmış ve laktasyon desteğinde yetenekli kişisel uzmanların, adölesanlar üzerinde etkisinin önemli olduğu bildirilmiştir. Adölesanlar için, planlı emzirme eğitim programlarının, emzirmenin başlatılmasında ve devam ettirilmesinde yararlı olduğu ifade edilmiştir. ${ }^{73}$ Emzirmeyi teşvik etmenin, adölesan kadınlar ve ailelerinin geliștirilmesi için önemli bir adım olduğu ifade edilmiştir. ${ }^{74}$ Pentecost ve Grassley'in yaptığı çalışmada (2014), ${ }^{75}$ adölesan anneler hemşirelerden, ne zaman emzirmeleri gerektiğini açıklamalarını, sorularını cevaplandırmalarını ve sürekli bilgi sağlamalarını beklediklerini ifade etmişlerdir. Adölesanlar ayrıca, hemşirelerin kendileriyle emzirme hakkında konuşmalarından ve zaman geçirmelerinden mutluluk duyduklarını belirtmişlerdir. ${ }^{75}$ Güçlü 
sosyal destek, adölesan annelerin emzirme süresini belirgin olarak etkiler. Bilgi paylaşımı, emzirmeyi kolaylaştırıcı teknikler ve emzirmeyle ilgili duygusal destek adölesanlar için gereklidir. İlk hafta ve ilk ay içerisindeki duygusal destek emzirmeyi öğrenmedeki yetenek ve çabalarını artırmayı sağlar. ${ }^{17,24,54,76,77}$ Randomize kontrollü bir çalışmada ise, ikinci trimesterde başlatılan ve postpartum 4 hafta süren akran desteği ve profesyonel desteğin emzirme süresini pozitif olarak etkilediği bulunmuştur. ${ }^{40}$ Çeşitli çalışmalarda, adölesanların emzirme oranlarını artırmak için ek olarak destek ve eğitimin gerekli olduğu gösterilmiştir. ${ }^{40,78}$ Ayrıca adölesanların, anne sütünün yenidoğan sağlığına ilişkin faydalarını algılamalarının, emzirmeye karşı motivasyonlarının artmasına neden olduğu, emzirmeye başlama oranı ve emzirme süresini arttırdığı belirlenmiştir. ${ }^{17,24}$

Gelişmekte olan ülkelerdeki adölesanlar arasında, erken gebelikleri ve kötü üreme sonuçlarını önleme ile ilgili Dünya Sağlık Örgütü'nün, 2011 yılında yayınladığı rehberde 6 sonuç bildirilmiştir. Bu kapsamda; 18 yaşından önce olan evliliklerin azaltılması, 20 yaşından önceki gebelikleri azaltmak için anlayış ve destek oluşturulması, kontrasepsiyon kullanımının artırılması, adölesanlar arasındaki istek dışı zorla gerçekleşen cinsel ilişkinin azaltılması, güvenli olmayan düşükleri azaltmak ve nitelikli antenatal, doğum ve postpartum bakım oranını artırmak amaçlanmıştır. ${ }^{79}$ Adölesan gebeliklerin önlenmesi açısından yapılacak çalışmalar birincil, ikincil ve üçüncül koruma şeklinde planlanabilir. Birincil koruma kapsamında; politikacılarla işbirliği içerisinde erken evliliklerin yasalarla önüne geçilmesini sağlama, kızların bilgilendirilmesi ve güçlendirilmesi, kız çocuklarının okula devam oranını artırma, erken evliliği destekleyen kültürel normlara etki etme çalışmaları yapılabilir. Ayrıca, adölesanlar arasında gebeliği önleme programları desteklenmeli, kız ve erkek çocuklarına cinsellik hakkında eğitim planlanmalı, kontrasepsiyon kullanımını artırmak amacıyla okullarda aile planlaması ve ilişkili konuları içeren eğitimlerin yapılması, hayır deme hakkı üzerine eğitimlerin verilmesi gerekmektedir. ${ }^{79,80} \mathrm{Bu}$ konuda adölesanın kendisi, akran çevresi, ailesi, sağlık profesyonelleri ve devlet işbirliği içerisinde çalışmalıdır. ${ }^{80}$ İkincil koruma, adölesanın doğum kontrol için sağlık perofesyonellerine başvurması durumunda verilen eğitimleri ve hizmetleri kapsamaktadır. Kontrasepsiyon ile ilgili olan eğitimlerde aile ile işbirliği yapılırken, adölesanın verdiği tepki dikkatle izlenmelidir. Ebeveynlerin, bu rehberliğe katılması adölesanın merkezlere başvurmasını önleyip, bu konuda cesaretinin kırılmasına yol açabilir. $^{79,80}$ Ergenlerin, gebelikten korunma hizmeti alabilmesi için olanakları artırma, adölesanlar için kontraseptiflerin maliyetini azaltma ya da ücretsiz temin etme ve bu konuda yasama yapılması sağlanabilir. Üçüncül koruma ise, gebe olan adölesanları hedeflemekte ve gebe adölesanlar arasındaki kötü üreme sonuçlarını önleme ile ilgilidir. Adölesanların, güvenli küretaj ve küretaj sonrası hizmetlere erişimini etkinleştirmek, adölesanları yasal küretaj hizmetlerini nereden edinecekleri konusunda bilgilendirmek, güvensiz küretaj tehlikelerine ilişkin toplum bilincini artırmak önemlidir. Nitelikli antenatal, doğum ve postpartum bakım kullanımının artırılması konusunda adölesanları bilgilendirmek ve erken prenatal takip uygulamak gebeliğin olumsuz sonuçlarının önlenmesinde yararlı ve etkili olabilmektedir. ${ }^{79}$ Adölesan annelerin ve anne adaylarının, ihtiyaçlarına karşı hassas ve duyarlı olmak gerekir. Hem fiziksel, hem de psikolojik durumlarının tam gelişmemiş olması ve değişken duygusal durumları nedeniyle, adölesanlarda erken prenatal bakımın önemi bir kat daha artmaktadır. Postpartum bakımda, adölesanları erken ve sık takip etmek ve emzirme konusunda desteklemek emzirme oranları açısından da katkı sağlayabilmektedir. Bu açıdan, birinci basamak sağlık hizmetleri kapsamında emzirme konusunda eğitimler düzenlemek, postpartum ev ziyaretleri yapmak ve emzirme danışmanlığı sağlamak önemlidir.

\section{SONUC ve ÖNERILERR}

\section{Araştırmacılar İçin Öneriler}

Literatürde, adölesan anneler ile yapılan çalışmaların genellikle adölesan annelerdeki emzirme oranlarını, emzirmeye başlamaya engel olan ve emzirmeyi kolaylaştıran faktörleri belirlemeye yönelik olduğu görülmüş, adölesan annelerde emzirmeye başlama, emzirmeyi sürdürme ve yenidoğanı sadece anne sütü ile besleme oranlarının düşük olduğu bulunmuştur. Adölesan annelerin, emzirme öz yeterliliği konusunda yapılan araştırmalar ise sınırlıdır. $\mathrm{Bu}$ konuda çalışmalar yapılarak literatüre katk1 sağlanabilir.

\section{Sağlık Çalışanları İçin Öneriler}

Dezavantajlı bir grup olan adölesan annelerin, emzirme konusunda sağlık profesyonelleri tarafindan desteklenmesi gerekmektedir. Özellikle adölesan annelerin, doğum öncesi dönemde başvurabilecekleri doğuma hazırlık sınıflarının olması ve bu sinıflarda emzirme eğitimlerinin verilmesi, bu grupta emzirme oranını, süresini ve emzirme öz yeterliliğini arttırmaya katk1 sağlayabilir.

Adölesan Anneler ve Yakınları İçin Öneriler 
Sağlık profesyonelleri dıșında, aile içerisinde emzirme dayanışmasını artırmak için, babaların da bu konuda desteklenmesi gerekir. Adölesan babaların, olumlu emzirme tutumları, annelerin emzirme davranışlarını etkilemektedir. Babaların bilgi eksikliğinin giderilip, anneleri bu konuda desteklemeleri emzirme oranlarının artmasına katkıda bulunabilir.

\section{KAYNAKLAR}

1. Borise, S. (Ed.). Adolescent sexual and reproductive health toolkit for humanitarian settings: A companion to the inter-agency field manual on reproductive health in humanitarian settings. United Nations Fund for Population Activities UNFPA 2009;1-8. https://www.unfpa.org/sites/default/files/pubpdf/UNFPA_ASRHtoolkit_english.pdf (Erişim tarihi: 06. 09. 2016)

2. World Health Organization (WHO). Adolescents: health risks and solutions. 2016 http://www.who.int/mediacentre/factsheets/fs3 45/en/ (Erişim tarihi: 06.09.2016)

3. United Nations Populations Fund (UNFPA). Girlhood, Not Motherhood. Preventing Adolescent Pregnancy 2015;1-30. https://www.unfpa.org/sites/default/files/pubpdf/Girlhood_not_motherhood_final_web.pdf (Erişim tarihi: 06. 09. 2016)

4. American Psycological Association (APA). Devoloping adolescents: A reference for professionals 2002;1-20. https://www.apa.org/pi/families/resources/deve lop.pdf (Erişim tarihi: 06. 09. 2016)

5. Skinner H, Biscope S, Poland B, Goldberg E. How adolescents use technology for health information: Implications for health professionals from focus group studies. J Med Internet Res 2003;5(4):e32.

6. MacKay AP, Duran C. Adolescent health in the United States, 2007. National Center for Health Statistics. 2007;1-10. http://www.cdc.gov/nchs/data/misc/adolescent 2007.pdf Date accessed: 06.09.2016

7. World Health Organization (WHO). Adolescent pregnancy. 2014 http://www.who.int/mediacentre/factsheets/fs3 64/en/ (Erişim tarihi: 06. 09. 2016)

8. Türkiye Nüfus ve Sağlık Araştırması (TNSA). Hacettepe Üniversitesi Nüfus Etütleri Enstitüsü 2013;70-73. Ankara, Türkiye.

9. Türkiye İstatistik Kurumu (TÜİK). Doğum İstatistikleri. 2015 http://www.tuik.gov.tr/PreHaberBultenleri.do?i $\mathrm{d}=21514$ (Erişim tarihi: 06. 09. 2016)

10. Anthony, D. The state of the world's children 2011- adolescence: An age of opportunity. United Nations Children's Fund (UNICEF.
www.unicef.org/sowc2011/pdfs/SOWC-2011-

Main Report_EN_02092011.pdf Date accessed: 06.09.16

11. World Health Organization. Pregnant adolescents: Delivering on global promises of hope. 2006;4-7. http://apps.who.int/iris/bitstream/10665/43368/ 1/9241593784_eng.pdf Date accessed: 06.09 .16

12. Olausson $\mathrm{P}$, Cnattingius $\mathrm{S}$, Haglund $\mathrm{B}$. Teenage pregnancies and risk of late fetal death and infant mortality. Obstetrical \& Gynecological Survey 1999;54(8):484-485.

13. Chen $X$, Wen S, Fleming N, Demissie K, Rhoads G, Walker M. Teenage pregnancy and adverse birth outcomes: a large population based retrospective cohort study. International Journal of Epidemiology 2007;36(2):368-373.

14. Shrim A, Ates S, Mallozzi A, Brown R, Ponette V, Levin I et al. Is young maternal age really a risk factor for adverse pregnancy outcome in a canadian tertiary referral hospital ? Journal of Pediatric and Adolescent Gynecology 2011;24(4):218-222.

15. Leclair E, Robert N, Sprague A, Fleming N. Factors associated with breastfeeding initiation in adolescent pregnancies: A cohort study. Journal of Pediatric and Adolescent Gynecology 2015;28(6):516-521.

16. Victora C, Bahl R, Barros A, França G, Horton $\mathrm{S}$, Krasevec $\mathrm{J}$ et al. Breastfeeding in the $21 \mathrm{st}$ century: epidemiology, mechanisms, and lifelong effect. The Lancet 2016;387(10017):475-490.

17. Wambach K, Cohen S. Breastfeeding experiences of urban adolescent mothers. Journal of Pediatric Nursing 2009;24(4):244254.

18. Britton J, Britton $\mathrm{H}$, Gronwaldt V. Breastfeeding, sensitivity, and attachment. Pediatrics 2006;118(5):e1436-e1443.

19. World Health Organization (WHO). Infant and young child feeding. 2016. http://www.who.int/mediacentre/factsheets/fs3 42/en/ (Erişim tarihi: 06. 09. 2016)

20. American Academy of Pediatrics Section on Breastfeeding. Breastfeeding and the use of human milk. Pediatrics 2012; 129(3):e827e841.

21. Bartick M, Reinhold A. The burden of suboptimal breastfeeding in the United States: A pediatric cost analysis. Pediatrics 2010;125(5):e1048-e1056.

22. Sipsma H, Biello K, Cole-Lewis H, Kershaw T. Like father, like son: The intergenerational cycle of adolescent fatherhood. Am J Public Health 2010;100(3):517-524. 
23. Lavender T, Thompson S, Wood L. Supporting teenage mothers with breastfeeding guardians. Br J Midwifery 2005;13(6):354-359.

24. Hannon $\mathrm{P}$, Willis S, Bishop-Townsend V, Martinez I, Scrimshaw S. African-American and Latina adolescent mothers' infant feeding decisions and breastfeeding practices: A qualitative study. Journal of Adolescent Health 2000;26(6):399-407.

25. Brown A, Raynor P, Lee M. Young mothers who choose to breast feed: the importance of being part of a supportive breast-feeding community. Midwifery 2011;27(1):53-59.

26. Sipsma H, Magriples U, Divney A, Gordon D, Gabzdyl E, Kershaw T. Breastfeeding behavior among adolescents: Initiation, duration, and exclusivity. Journal of Adolescent Health 2013;53(3):394-400.

27. Martin J, Hamilton BE, Sutton PD, Ventura SJ, Menacker F, Kirmeyer S, Mathews TJ. Births: Final data for 2006. National Vital Statistics Reports 2009;57(7):1-25.

28. Central for Disease Breastfeeding Report Card, 2014;1-8.

http://www.cdc.gov/breastfeeding/pdf/2014bre astfeedingreportcard.pdf Date accessed: 06.09.2015.

29. Central for Disease Breastfeeding Report Card, 2011;1-4

https://www.cdc.gov/breastfeeding/pdf/2011br eastfeedingreportcard.pdf Date accessed: 06.09.2015.

30. Fleming $\mathrm{N}, \mathrm{Ng} \mathrm{N}$, Osborne $\mathrm{C}$, Biederman $\mathrm{S}$, Yasseen A, Dy J et al. Adolescent pregnancy outcomes in the province of ontario: A cohort study. Journal of Pediatric and Adolescent Gynecology 2013;26(2):e55.

31. Dunn S, Bottomley J, Ali A, Walker M. 2008 Niday Perinatal database quality audit: report of a quality assurance project. Chronic Dis Inj Can 2011; 32:32

32. Bolling K, Grant C, Hamlyn B, Thornton A. Infant feeding survey 2005. 20071-20. http://www.hscic.gov.uk/catalogue/PUB00619/ infa-feed-serv-2005-rep.pdf Date accessed: 06.09 .16

33. Santo L, de Oliveira L, Giugliani E. Factors associated with low incidence of exclusive breastfeeding for the first 6 months. Birth 2007;34(3):212-219.

34. Dennis C, Heaman M, Mossman M. Psychometric testing of the breastfeeding selfefficacy scale-short form among adolescents. Journal of Adolescent Health 2011;49(3):265271.

35. Hunter L. Teenagers' experiences of postnatal care and breastfeeding. $\mathrm{Br} \mathrm{J}$ Midwifery 2008;16(12):785-790.

36. Fleming $\mathrm{N}, \mathrm{Tu} \mathrm{X}$, Black A. Improved obstetrical outcomes for adolescents in a community-based outreach program: A matched cohort study. Journal of Obstetrics and Gynaecology Canada 2012;34(12):11341140.

37. Glass T, Tucker K, Stewart R, Baker T, Kauffman R. Infant feeding and contraceptive practices among adolescents with a high teen pregnancy rate: A 3-year retrospective study. Journal of Women's Health 2010;19(9):16591663.

38. Lavender T, Thompson S, Wood L. Supporting teenage mothers with breastfeeding guardians. Br J Midwifery 2005;13(6):354-359.

39. Tucker C, Wilson E, Samandari G. Infant feeding experiences among teen mothers in North Carolina: Findings from a mixedmethods study. Int Breastfeed J 2011;6(1):14.

40. Wambach K, Aaronson L, Breedlove G, Domian E, Rojjanasrirat W, Yeh H. A randomized controlled trial of breastfeeding support and education for adolescent mothers. Western Journal of Nursing Research 2010;33(4):486-505.

41. de Oliveira L, Giugliani E, Santo L, Nunes L. Counselling sessions increased duration of exclusive breastfeeding: a randomized clinical trial with adolescent mothers and grandmothers. Nutrition Journal 2014;13(1):17.

42. Dykes F, Moran V, Burt S, Edwards J. Adolescent mothers and breastfeeding: experiences and support needs-an exploratory study. Journal of Human Lactation 2003;19(4):391-401.

43. Avery AB, Magnus JH. Expectant fathers' and mothers' perceptions of breastfeeding and formula feeding: A focus group study in three us cities. Journal of Human Lactation 2011;27(2):147-154.

44. Bäckström CA, Wahn EIW, Ekström AC. Two sides of breastfeeding support: experiences of women and midwives. Int Breastfeed $\mathbf{J}$ 2010;5(1):20.

45. Cricco-Lizza R. Everyday nursing practice values in the NICU and their reflection on breastfeeding promotion. Qualitative Health Research 2011;21(3):399-409.

46. Woods N, Chesser A, Wipperman J. Describing adolescent breastfeeding environments through focus groups in an urban community. Journal of Primary Care \& Community Health 2013;4(4):307-310.

47. Apostolakis-Kyrus K, Valentine C, De Franco E. Factors associated with breastfeeding initiation in adolescent mothers. The Journal of Pediatrics 2013;163(5):1489-1494.

48. Li R, Fein S, Chen J, Grummer-Strawn L. Why mothers stop breastfeeding: mothers' selfreported reasons for stopping during the first 
year. Pediatrics 2008;122(Supplement):S69S76.

49. Ogbuanu C, Glover S, Probst J, Liu J, Hussey J. The effect of maternity leave length and time of return to work on breastfeeding. Pediatrics 2011;127(6):e1414-e1427.

50. Nelson A. Adolescent attitudes, beliefs, and concerns regarding breastfeeding. The American Journal of Maternal/Child Nursing 2009;34(4):249-255.

51. Thomas J. Barriers to exclusive breastfeeding among mothers during the first four weeks postpartum. Doctoral Thesis. Walden University 2016;1-40.

52. Yılmaz E, Yılmaz Z, Işık H, Gültekin I, Timur H, Kara $F$ et al. Factors associated with breastfeeding initiation and exclusive breastfeeding rates in turkish adolescent mothers. Breastfeeding Medicine 2016;11(6):315-320.

53. Smith HP, Coley S, Labbok M, Cupito S, Nwokah E. Early breastfeeding experiences of adolescent mothers: a qualitative prospective study. Int Breastfeed J 2012;7(1):13.

54. Nelson A, Sethi S. The breastfeeding experiences of canadian teenage mothers. Journal of Obstetric, Gynecologic \& Neonatal Nursing 2005;34(5):615-624.

55. Bailey C, Pain R, Aarvold J. A 'give it a go' breast-feeding culture and early cessation among low-income mothers. Midwifery 2004;20(3):240-250.

56. McFadden, AToole G. Exploring women's views of breastfeeding: a focus group study within an area with high levels of socioeconomic deprivation. Maternal and Child Nutrition 2006;2(3):156-168.

57. Mitra A, Khoury A, Hinton A, Carothers C. Predictors of breastfeeding intention among low-1ncome women. Maternal and Child Health Journal 2004;8(2):65-70.

58. Dennis C. Theoretical underpinnings of breastfeeding confidence: a self-efficacy framework. Journal of Human Lactation 1999;15(3):195-201.

59. Bandura A. Health promotion from the perspective of social cognitive theory. Psychology \& Health 1998;13(4):623-649.

60. Mossman M, Heaman M, Dennis C, Morris M. The influence of adolescent mothers' breastfeeding confidence and attitudes on breastfeeding initiation and duration. Journal of Human Lactation 2008;24(3):268-277.

61. Andrade IG, Taddei JA. Social-economical, cultural and family determinants in the city of Natal, Brazil. Rev Paul Pediatr 2002;20(8):16

62. Susin LR, Giugliani ER, Kummer SC. Influence of grandmothers on breastfeeding practices. Rev Saude Publica 2005; 39:141147.
63. Chang Y, Valliant M, Bomba A. Gender differences in knowledge and attitude regarding breastfeeding. International Journal of Consumer Studies 2012;36(3):342-351.

64. Sherriff N, Hall V, Panton C. Engaging and supporting fathers to promote breast feeding: A concept analysis. Midwifery 2014;30(6):667677.

65. Rosane Odeh Susin L, Regina Justo Giugliani E. Inclusion of fathers in an intervention to promote breastfeeding: impact on breastfeeding rates. Journal of Human Lactation 2008;24(4):386-392.

66. Kang N, Song Y, Im E. Korean university students' knowledge and attitudes toward breastfeeding: A questionnaire survey. International Journal of Nursing Studies 2005;42(8):863-870.

67. Grady MA, Bloom KC. Pregnancy outcomes of adolescents enrolled in a centering pregnancy program. J Midwifery Women Health 2004; 49:412-20.

68. Greenwood K, Littlejohn P. Breastfeeding intentions and outcomes of adolescent mothers in the starting out program. Breastfeed Rev 2002; 10:19-23.

69. Quinlivan JA, Box H, Evans SF. Postnatal home visits in teenage mothers: A randomised controlled trial. Lancet 2003; 361:893-900.

70. Volpe E, Bear M. Enhancing breastfeeding initiation in adolescent mothers through the Breastfeeding Educated and Supported Teen (BEST) Club. Journal of Human Lactation 2000;16(3):196-200.

71. Monteiro J, Dias F, Stefanello J, Reis M, Nakano A, Gomes-Sponholz F. Breast feeding among Brazilian adolescents: Practice and needs. Midwifery 2014;30(3):359-363.

72. Grassley JS. Adolescent mothers' breastfeeding social support needs. JOGNN 2010; 39:713-722

73. Hall Moran V, Edwards J, Dykes F, Downe S. A systematic review of the nature of support for breast-feeding adolescent mothers. Midwifery 2007;23(2):157-171.

74. Sipsma HL, Jones KL, Cole-Lewis H. Breastfeeding among adolescent mothers: a systematic review of interventions from highincome countries. Journal of Human Lactation. 2015;31(2):221-229

75. Pentecost R, Grassley JS. Adolescents' needs for nurses' support when initiating breastfeeding. Journal of Human Lactation. 2014;30(2):224-228

76. Dykes F, Moran V, Burt S, Edwards J. Adolescent mothers and breastfeeding: experiences and support needs-an exploratory study. Journal of Human Lactation 2003;19(4):391-401. 
77. Spear HJ. Breastfeeding behaviors and experiences of adolescent mothers. The American Journal of Maternal/Child Nursing 2006;31(2):106-113.

78. Meglio G, McDermott M, Klein J. A randomized controlled trial of telephone peer support's influence on breastfeeding duration in adolescent mothers. Breastfeeding Medicine 2010;5(1):41-47.

79. World Health Organization. Who guidelines on preventing early pregnancy and poor reproductive outcomes among adolescents in developing countries 2011;1-8.

80. Uzun AK, Orhon FŞ. Adolesan gebeliklerin anne ve bebek sağlığına olan etkileri. Journal of Ankara University Faculty of Medicine 2013;66(1):19-24. 